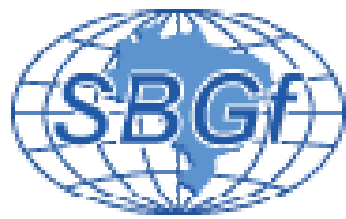

\title{
Simultaneous inversion of hypocentres and crustal model in João Câmara, north- eastern region of Brazil
}

Celia Fernandes $^{1}$, Jesus Berrocal ${ }^{1}$, Mario Takeya ${ }^{2}$,Francisco H. R. Bezerra ${ }^{3}$ Pedro M. A Barros ${ }^{1}$ and Josimar A Silva $^{1}$

${ }^{1}$ Instituto de Astronomia, Geofísica e Ciências Atmosféricas, Universidade de São Paulo.

${ }^{2}$ Depto. de Física Teórica e Experimental, Universidade Federal de Rio Grande do Norte (UFRN).

${ }^{3}$ Depto. de Geologia, Universidade Federal de Rio Grande do Norte.

\section{Resumo}

Using the simultaneous inversion method, hypocenters and a structural model related to a seismic sequence in João Câmara beginning in 1986 were determined..Stable solutions for the simultaneous inversion were obtained after about 400 iterations for the northern and central portions and 53 for the southern portion. The spatial distribution of those hypocentres and the composite focal mechanism solutions suggest a correlation with a dextral transcurrent fault, with a small normal component segmented in at least three no-coplanar portions with a dominant strike of around $41^{\circ}$. The dip angle, oriented to the NW, changes from $76^{\circ}$ in the northern portion to $66^{\circ}$ in the southern one; whereas the slip angle increases from $10^{\circ}$ to $35^{\circ}$ from northern to southern portions. The spatial distribution of those events seems to correlate well with the surface tectonic features existent in the area, and with the regional stress pattern.

\section{Introduction}

An important cycle of seismic activity occurred in João Câmara, NE region of Brazil, which begun during the second half of 1986, and lasted for several years producing more than 50.000 small magnitude earthquakes. The most important event of this cycle $\left(m_{b}\right.$ 5.1 and intensity VII MM) occurred on 1986.11.30. Ferreira, et al., 1987; Takeya et al., 1989, among others, associated this activity to a $28 \mathrm{~km} \mathrm{~N} 40^{\circ} \mathrm{E}$ fault called Samambaia Fault. A semi-space model with a constant $6.2 \mathrm{~km} / \mathrm{s} P$ wave velocity, and $V_{P} / V_{S}$ of 1,73 , was used in those studies for hypocentral determinations. Using a simultaneous inversion method, hypocentres and a structural model related to the seismic cycle in João Câmara, were obtained in this work.

Data of little more than 300 aftershocks recorded from June to September 1987 in a local nine-stations network installed by Cardiff and UFRN universities, are used in this experiment. Seismograms were obtained on a portable multi-channel analogue magnetic tape recorder that permitted automatic digitalisation, which allowed precise reading of time arrivals ( $\pm 0.01 \mathrm{~s}$ ) using the
GIANT package (Rietbrock \& Scherbaum, 1998). The inverted hypocentres, obtained simultaneously with a layered structure, are considered to be more precise than the ones calculated with the semi-space model, therefore, they will allow a better correlation with local tectonic features, as it is shown in this paper.

\section{Geological Setting}

The Borborema province that comprises most of Brazil's $\mathrm{NE}$ region consists of a tectonic collage of basement rocks of Paleoproterozoic age involving small Archean nuclei and Paleo to Neoproterozoic volcano-sedimentary belts. The epicentral area (see Fig. 1) is on the border of Late Cretaceous sedimentary Potiguar basin that overlays the Precambrian shield.

Large Late Precambrian SW-NE transcurrent ductile shear zones divide the shield in this region. These structures separate huge slices with distinct supra-crustal or infra-crustal rock domains. The shear zones have been reactivated during Cretaceous and Cenozoic times as brittle structures. Identification of these slices beneath Potiguar basin, imply a systematic eastwards bending of their borders suggesting a dextral drag pattern. Those slices were called "piano key" structure by Fortes (1986).

The Borborema province: which consists of a tectonic collage of basement rocks of Paleoproterozoic age involving small Archean nuclei and Paleo- to Neoproterozoic volcano-sedimentary belts. A network of transcurrent shear-zones intruded by granodioritic plutons and dike-swarms, perhaps resulting from the eastward escape of this province during the collision of the Amazonia and São Francisco cratons, characterizes the region The Borborema province is tectonically active and displays the highest level of seismic activity in Brazil, which consists of earthquake swarms with events up to $m_{b}$-5.2. Strikingly, according to recent neotectonic studies, events up to $m_{b} \sim 7.0$ could have happened in the area (Bezerra et al., 2005). 


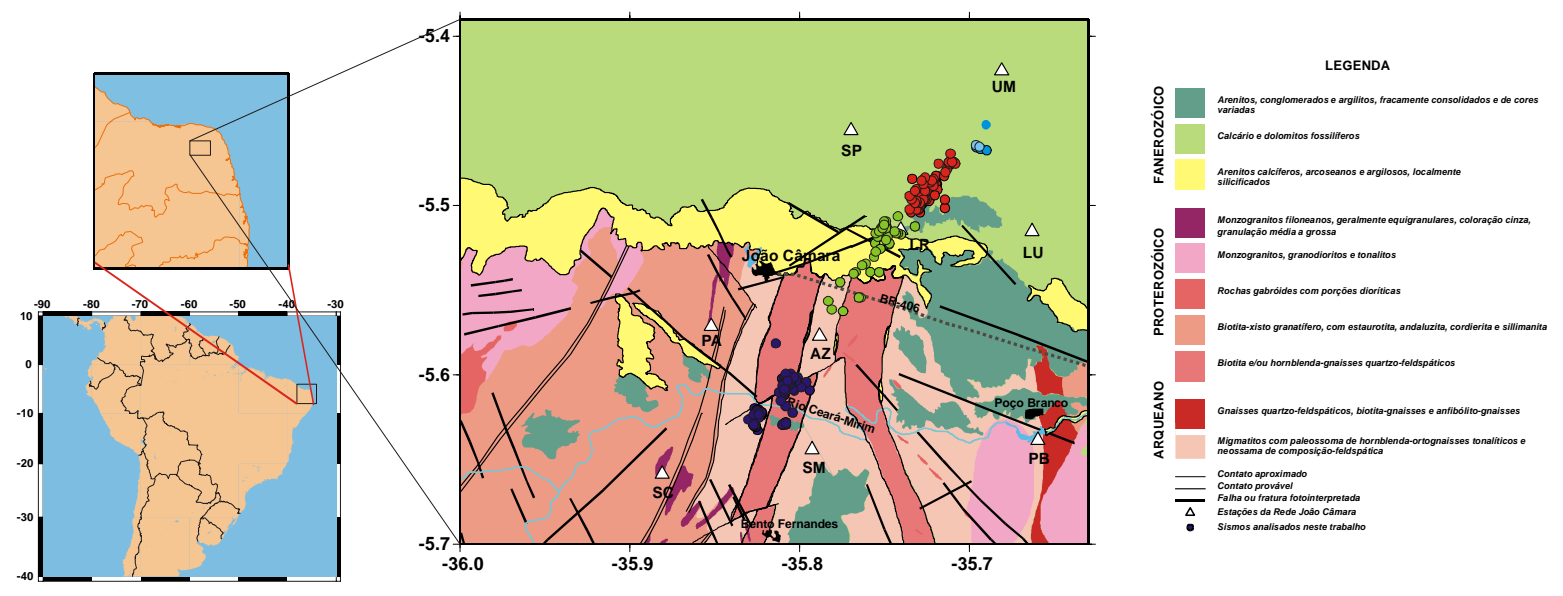

Figure 1 - Map of Epicentre area and geology.

\section{Methodology}

The simultaneous inversion of hypocentres and structure method is based in the principle that seismic waves arrival times to the seismographic network stations depend of the structural model beneath the recording network, and on the hypocentral parameters, both of which can be calculated simultaneously, from arrival time readings of an appropriate number of local earthquakes, using an inversion method.

Crosson (1976) simultaneous inversion method uses the concept of seismic rays travelling through a flat-layered media with constant velocity in each layer, for which the travel-time from the focus to the recording station is calculated. With a reasonable number of recording stations, and a large number of local earthquakes, the number of unknowns is normally smaller than the number of equations, which are solved by the least square method. The program used in this work receives as input the hypocentral results from HYPO71 program (Lee \& Lahr, 1975), and the corresponding original time arrival used in that program.

\section{Results}

Stable solutions for the simultaneous inversion were obtained after about 400 iterations for the northern portion and 53 for the southern portion (See Fig. 2). The mean structural model along those portions, until the depth where the events occurred, is as follow:

\begin{tabular}{|c|c|}
\hline DEPTH & P VELOCITY \\
\hline $0 \mathrm{~km}$ & $5.78 \mathrm{~km} / \mathrm{s}$ \\
\hline $3.6 \mathrm{~km}$ & $5.89 \mathrm{~km} / \mathrm{s}$ \\
\hline $5.3 \mathrm{~km}$ & $5.50 \mathrm{~km} / \mathrm{s}$ \\
\hline $6.5 \mathrm{~km}$ & $6.20 \mathrm{~km} / \mathrm{s}$ \\
\hline
\end{tabular}

Partial northern and southern models present nearly the same characteristics, except the low velocity at $5.3 \mathrm{~km}$ of depth is slightly thicker in the northern portion.

The resulting epicentres from the inversion process are shown in the seismotectonic map of Fig. 1, where the epicentres have been separated in Northern (red), Central (green) and Southern (blue) portions, limited by latitudes $05.507^{\circ} \mathrm{S}$ and $05.577^{\circ} \mathrm{S}$, respectively. In this map it is possible to separate from the Northern portion a small group of epicentres in its northern extreme, which seems to have a different trend than main Northern portion.

Those portions apparently seem to be part of a single straight fault oriented to NE. To see if this is true, it will be necessary to construct some sections to see the spatial distribution of those hypocentres. 


\section{Northern portion}
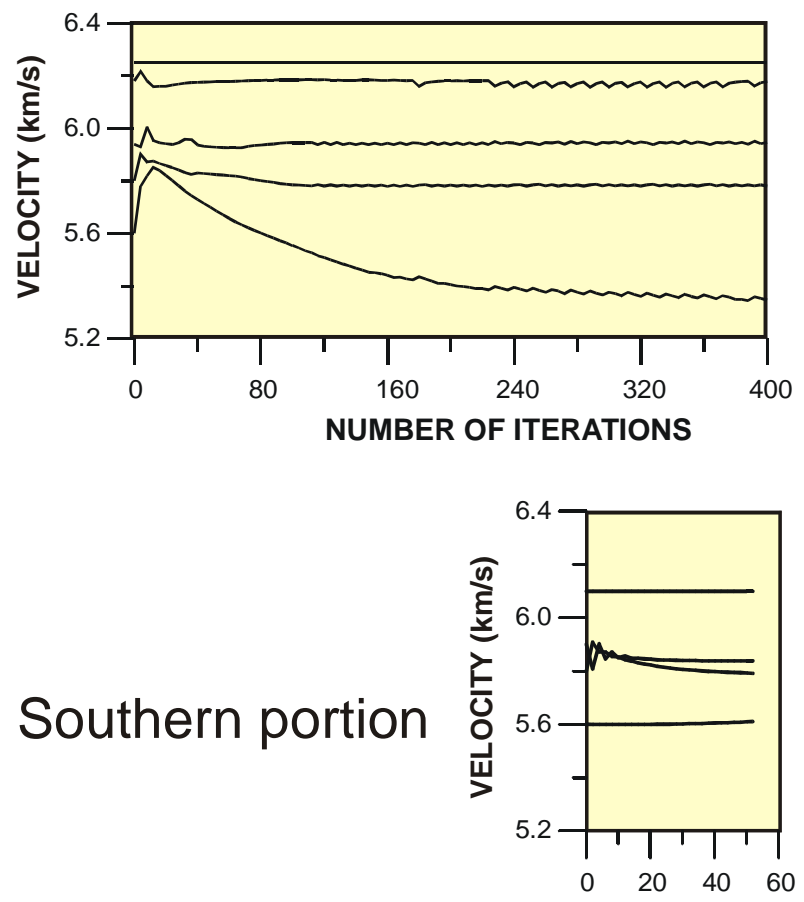

NUMBER OF ITERATIONS

Figure 2 - Iteration numbers

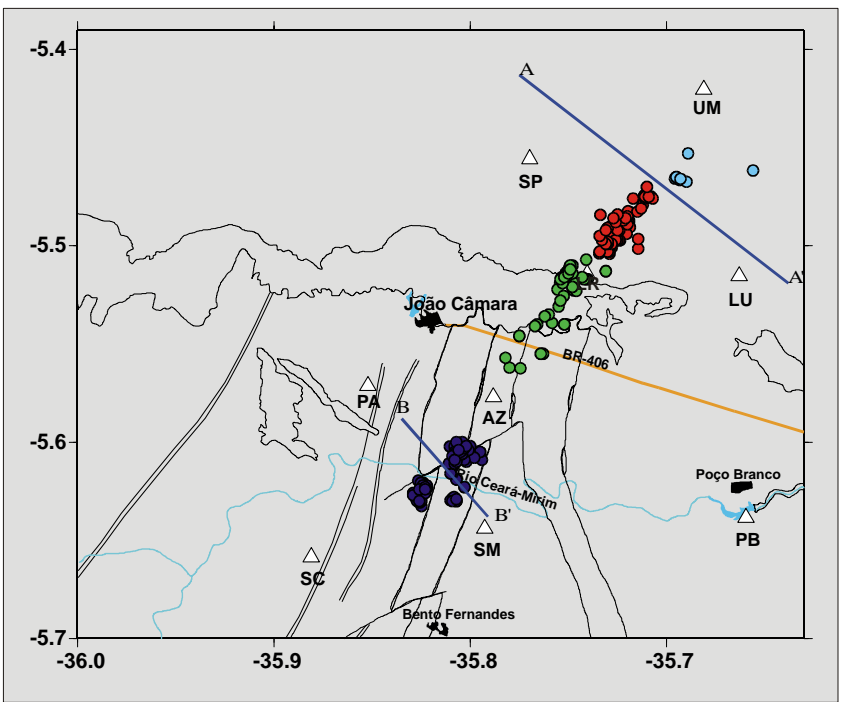

Figure 3 - Epicentres areas and faults

Hypocentres projected in plane $A A^{\prime}$, perpendicular to the fault trend, are shown separately for the three portion in sections of Fig. 4. Northern and Central portions have the same $80^{\circ}$ dip to NW, however Southern portion hypocentres distribution is diffuse in this projection, suggesting they do not belong to the same fault of Northern and Central portions.

The activity in the Southern portion clearly do no belong to the fault formed by the Central and Northern portions of
João Câmara seismic activity, therefore the proposed Samambaia Fault does not include the activity in this portion.

The association of Southern portion seismic activity to that old secondary fault is very important because suggests the probable reactivation of tectonic faults in the area where the João Câmara seismic activity has occurred. 

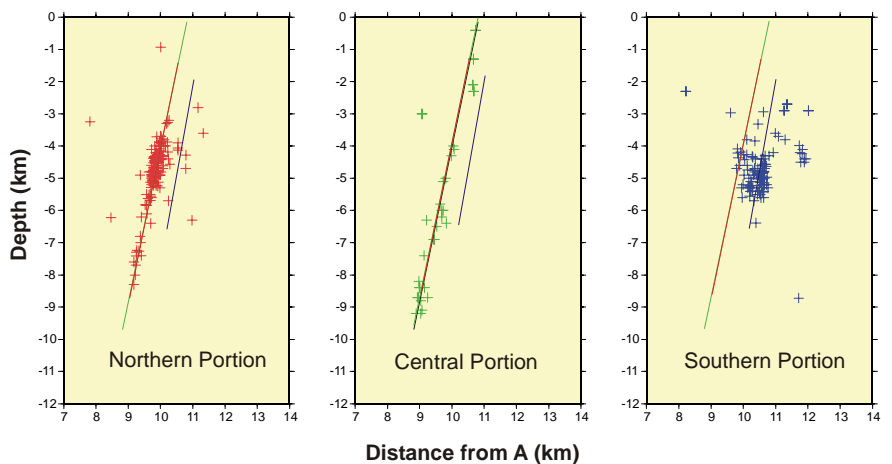

Figure 4 - Epicentres project in direction $\mathrm{AA}^{\prime}$

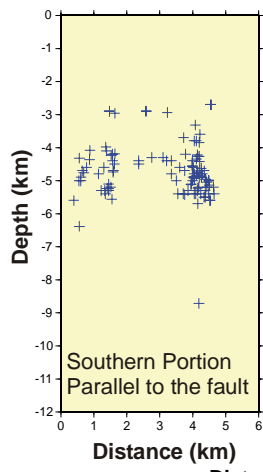

Distance from B (km)

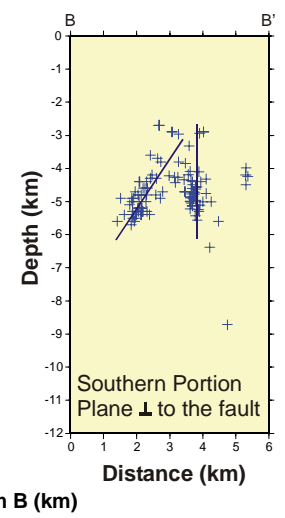

Figure 5 - Epicentres project in direction BB'.
Composed focal mechanisms were elaborated for Northern and Central portions and are shown in Fig. 6, together with focal mechanism of an event of Southern portion. The two composed solution present similar results, strike of N410E, and dip 760 to NW. The solution for Southern portion earthquake presents a strike of N63oE and dip 70o to NW. Those results agree well with the parameters found through the spatial distribution of hypocentres.

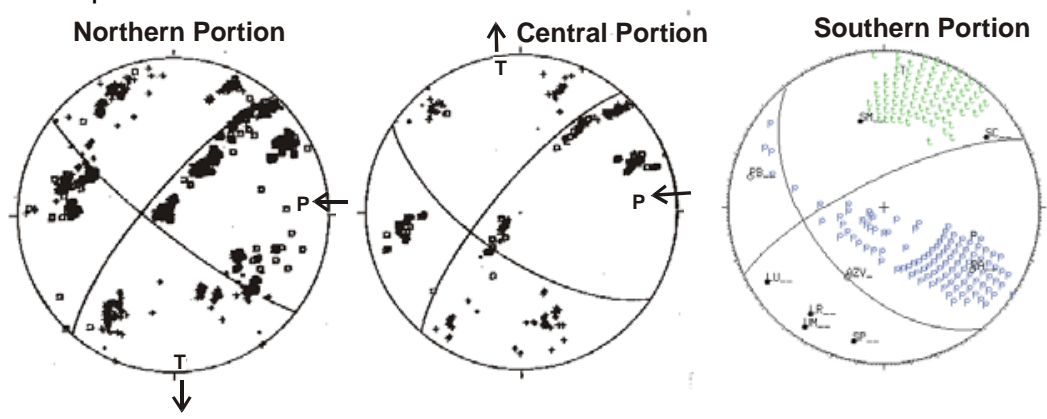

Figure 6 - Focal mechanisms.

\section{Conclusions}

The hypocentral determination using the simultaneous inversion method together with structure parameters has resulted in very precise seismic parameters for the sequence of earthquakes analysed in this work. The use of the facilities given by the GIANT package helped to perform an even, regular and fast picking up of $P$ and $S$ readings.

Spatial distribution of hypocentres performed in this work suggests the activity of João Câmara is associated to reactivation of old faults as it was presented in the analysis of Southern portion activity. The northern extreme of Northern portion seem to bend the Northern portion trend to $\mathrm{NE}$, following the proposed curvilinear "piano key" shape proposed by Fortes (1986), suggesting the reactivation of old tectonic features. Focal mechanism solution indicate main strike slip dextral faults with a small normal component.

Fernandes, Berrocal, Takeya, Bezerra, Barros and Silva

\section{References}

Croson, R.S., 1976. Crustal structure modelling of earthquake data. J. Geophys. Res., 81: 3036-3054

Ferreira, J.M et al., 1987. A continuing earthquake séquense near João Câmara, Northeast Brazil Preliminary results. Geophys. Res. Lett., 14: 1042-1045.

Fortes, F.P., 1986, A tectônica de teclas da Bacia Potiguar. Anais do XXXVI Congr. Brás. De Geologia, 3.1145-1153, Goiânia -GO.

Lee W. H. K. \& Lahr, J,C., 1975. HYPO71 (Revised): A computer program for determining hypocenter, magnitude , and first motion pattern of local earthquakes. U.S. Geological Survey, Open -File Report 75-313, 114p.

Rietbrock, A. \& Scherbaum, F., 1998. Short introduction to the software package GIANT 1.1Institut fur Allgemineund Angewandte Geophysik.

Takey M. et al., 1989. The 1986-1988 intraplate earthquake sequence near João Cãmara, NE BrazilEvolution of seismicity. Tectonophysics, 167:117-131. 